\title{
NAIRU Uncertainty and Nonlinear Policy Rules
}

\author{
Laurence H. Meyer ${ }^{*}$ \\ Eric T. Swanson ${ }^{* *}$ \\ Volker W. Wieland ${ }^{* * *}$
}

\begin{abstract}
Meyer (1999) has suggested that episodes of heightened uncertainty about the NAIRU may warrant a nonlinear policy response to changes in the unemployment rate. This paper offers a theoretical justification for such a nonlinear policy rule, and provides some empirical evidence on the relative performance of linear and nonlinear rules when there is heightened uncertainty about the NAIRU.
\end{abstract}

January 2, 2001

JEL Classification: E52, E24

*Governor, Board of Governors of the Federal Reserve System

${ }^{* *}$ Economist, Board of Governors of the Federal Reserve System

${ }^{* * *}$ Professor, Goethe Universität Frankfurt am Main

We appreciate helpful comments by David Small, Athanasios Orphanides, and others at the Federal Reserve Board. The views expressed in this paper are solely those of the authors and do not necessarily represent those of any other person in the Federal Reserve System. 


\section{Introduction}

Core inflation in the United States declined from the end of 1995 through the end of 1999 and has remained modest thereafter despite persistent above-trend growth and a decline in the unemployment rate to a level well below earlier estimates of the non-accelerating inflation rate of unemployment (NAIRU). ${ }^{1}$ These developments have had at least two implications for the conduct of monetary policy. First, policymakers - at least those that have continued to rely on the NAIRU framework - have had to update their estimates of the NAIRU as they have decided how much to adjust the federal funds rate in response to realizations in inflation and the unemployment rate. Second, policymakers have had to adjust the conduct of monetary policy to take into account the heightened uncertainty about the NAIRU.

Although a standard result in the literature on monetary policy under uncertainty is that of certainty equivalence, a recent strand of this literature has focused on the presence of a signal extraction problem in policymakers' estimation process. This part of the literature suggests that policymakers should attenuate their response to changes in the observed unemployment rate when they are uncertain about the NAIRU and, at the same time, respond more aggressively to movements in the inflation rate.

In addition, Meyer (1999, 2000a) has suggested that episodes of heightened uncertainty about the NAIRU may also warrant a nonlinear policy response to changes in the unemployment rate. Specifically, he has suggested that, in such circumstances, policymakers: (1) initially attenuate their response to changes in the unemployment rate, but (2) return to a more aggressive policy response when the unemployment rate moves far enough that policymakers feel more confident the prevailing unemployment rate is below the NAIRU. This paper is an attempt to offer theoretical justification for such a nonlinear policy rule and to provide some empirical evidence on the relative performance of linear and nonlinear rules when there is heightened uncertainty about the NAIRU.

\section{Optimal Nonlinear Policy}

To illustrate the basic point of the paper without introducing unnecessary complications, we use a very simple backward-looking model (in the simulations section below, we consider models with richer dynamics and rational expectations). The simple model consists of an "IS" type equation

1. The single most important contributor to the exceptional macroeconomic performance in recent years appears to be a dramatic increase in the economy's structural rate of productivity growth. Such an acceleration in productivity may have a temporary disinflationary effect that is reflected in a decline in the short-run relative to the long-run NAIRU. In this case, the heightened uncertainty about the NAIRU in recent years may be closely connected to the acceleration in productivity and to the real-time uncertainty about its effect on the short-run NAIRU. See Braun (1984) for an analytical foundation of the relationship between productivity and the NAIRU and Meyer (2000b) for an application to the recent period of an acceleration in productivity. The analysis in this paper holds equally well if the uncertainty is about the long-run or the short-run NAIRU. 
relating the lagged real interest rate $\mathrm{r}_{\mathrm{t}-1}$ to unemployment $\mathrm{u}_{\mathrm{t}}$, and a short-run Phillips curve that determines inflation $\pi_{\mathrm{t}}$ :

$$
\begin{gathered}
\left(\mathrm{u}_{\mathrm{t}}-\mathrm{u}^{*}\right)=\theta\left(\mathrm{u}_{\mathrm{t}-1}-\mathrm{u}^{*}\right)+\alpha\left(\mathrm{r}_{\mathrm{t}-1}-\mathrm{r}^{*}\right)+\varepsilon_{\mathrm{t}} \\
\pi_{\mathrm{t}}=\pi_{\mathrm{t}-1}-\beta\left(\mathrm{u}_{\mathrm{t}-1}-\mathrm{u}^{*}\right)+\mathrm{v}_{\mathrm{t}}
\end{gathered}
$$

$\mathrm{r}^{*}, \theta, \alpha$, and $\beta$ are known positive parameters, $\varepsilon_{\mathrm{t}}$ and $v_{\mathrm{t}}$ are stochastic disturbances, and $\mathrm{u}^{*}$ denotes the NAIRU. Policymakers never observe $u^{*}$ directly, but must infer it from observations of $u$ and $\pi$.

We maintain the standard assumption that policymakers' preferences are quadratic over inflation and unemployment gaps. Thus, optimal policy in terms of the real interest rate in this standard linear-quadratic model is given by:

$$
r_{t}=r^{*}+a\left(\pi_{t}-\pi^{*}\right)-b\left(u_{t}-E_{t} u^{*}\right)
$$

where $\pi^{*}$ is policymakers' target for inflation and a and b are functions of the parameters $\alpha, \beta$, and $\theta$. Note that this policy displays the usual property of certainty equivalence: interest rates are set based on policymakers' best estimates of the state of the economy, without regard to the uncertainty surrounding those estimates. ${ }^{2}$

Recently, some authors (Svensson and Woodford (2000), Swanson (2000a)) have focused attention on the process by which policymakers arrive at the estimate $\mathrm{E}_{\mathrm{t}} \mathrm{u}^{*}$. These authors have noted that, despite the certainty equivalence in equation (3), in terms of observable variables $\left(u_{t}\right.$, $\pi_{\mathrm{t}}, \mathrm{r}_{\mathrm{t}-1}$ and their lags), optimal policy will in general depend on the level of uncertainty surrounding these indicators. This is because policymakers' problem of estimating $\mathrm{u}^{*}$ is one of signal extraction, as in Lucas (1972). In a signal extraction problem, the signal-to-noise ratios of the indicator variables matter.

In this paper, we also focus on policymakers' estimation of $\mathrm{u}^{*}$. It is standard practice in the literature to assume that policymakers' priors, and all shocks in the model, have a Gaussian distribution. In this special case, policymakers' optimal filtering process for $u^{*}$ is linear in the observed variables $\left(u_{t}, \pi_{t}, r_{t-1}\right.$ and their lags). It is here, and only here, that we deviate from the standard assumptions in the literature.

Given the heightened uncertainty facing policymakers in the late 1990s, and the possibility of structural change, it seems natural to think of policymakers as having had beliefs about the NAIRU that, rather than being normally distributed, were instead more diffuse in a region around the mean. In Figure 1, we plot density functions for three distributions, which might be used to

2. We abstract from the relationship between the estimation of $u^{*}$ and the slope of the short-run Phillips curve $\beta$ by assuming that $\beta$ is known to the policymaker. Wieland (1998) considers the (non-certainty-equivalent) case where estimation of $u^{*}$ is tied to estimation of $\beta$. 
model policymakers' beliefs about the NAIRU during the early stages of this period. All the distributions have been centered around a mean of 5 for concreteness and comparability. The short-dashed line plots a Gaussian density, which is usually assumed in the literature. By contrast, the solid line plots a uniform density over the interval [4,6]; it implies a much greater degree of uncertainty about the NAIRU in a region around the mean, although it has the feature that policymakers are absolutely certain the true NAIRU lies neither below 4 nor above 6 . The long-dashed line in the figure presents an intermediate case-it has a density that is proportional to $\exp \left(-0.5\left(\mathrm{u}^{*}-5\right)^{4}\right)$. In this paper, we assume that the latter two distributions are more plausible models of policymakers' beliefs, and offer a better explanation for policymakers' behavior, over this recent historical episode. ${ }^{3}$

This is not to say, of course, that these distributions will remain fixed forever throughout time. Policymakers will naturally learn about $\mathrm{u}^{*}$ as events unfold, and so their beliefs should be regarded as evolving gradually toward normality, and even narrowing down to a single point if there were no shocks to $\mathrm{u}^{*}$ and no further structural change.

Given the non-Gaussian prior distributions in Figure 1, optimal updating matches the nonlinear prescriptions put forth by Meyer (1999). This is demonstrated by the solid lines in Figure 2, which present policymakers' optimal updates of $u^{*}$ in response to realized values of $u$ and $\pi$, assuming the uniform distribution for policymakers' priors from Figure 1 (the results for the long-dashed distribution in Figure 1 are similar). ${ }^{4}$ For comparison, the dashed lines in Figure 2 present the optimal updates for the Gaussian prior from Figure 1. Policymakers with a "diffuse-middled" prior, such as the uniform distribution, are very willing to revise their estimate of $\mathrm{u}^{*}$ when faced with small surprises in unemployment and inflation, but become increasingly more reluctant to revise their beliefs, at the margin, the more they have revised their estimate of u* already.

Note that the optimal updating in Figure 2 leads to a nonlinear interest rate policy in terms of observables $\left(\mathrm{u}_{\mathrm{t}}\right.$ and $\pi_{\mathrm{t}}$ ). This can be seen by plugging the optimal updates from Figure 2 into the estimate for $\mathrm{u}^{*}$ in equation (3). As a result, policymakers will be reluctant to raise (lower) the short-term interest rate in response to small declines (increases) in the unemployment rate. However, beyond some threshold policy will respond more actively.

In this paper, we focus exclusively on nonlinearities in the estimation of $\mathrm{u}^{*}$ for optimal monetary policy. There are other reasons why one might want to consider a nonlinear policy response

3. One could regard these distributions as the result of a structural shift in the economy that has been known to occur, or is thought to have occurred with some positive probability. Explicitly modeling this phenomenon is difficult, and is addressed to a very limited extent in Swanson (2000b). We do not pursue foundations for these prior distributions further in this paper.

4. These are cross-sections of the full bivariate signal extraction problem that is implied by the priors of Figure 1 and equations (1) and (2); see Swanson (2000b). We assume $\varepsilon_{\mathrm{t}}$ and $v_{\mathrm{t}}$ are Gaussian with $\sigma_{\varepsilon}=0.4$ and $\sigma_{v}=0.6$ in calculating Figure 2. 
function as well. For example, the equations describing the economy (such as the Phillips curve) might have important nonlinearities, or policymakers might have nonquadratic preferences (such as "zone" preferences for inflation), which are considered in Orphanides and Wieland (2000). However, for this paper we focus on the recent U.S. experience with heightened uncertainty about the NAIRU and the possibility of structural change.

\section{A Simple Nonlinear Updating Rule}

The optimal estimate of $\mathrm{u}^{*}$ shown in Figure 2 takes into account realizations of all observable variables in the model. In more complicated and realistic economic models, with a larger number of state variables, indicator variables, and forward-looking expectations, optimal updating with non-Gaussian priors becomes computationally intractable. Moreover, it assumes an unrealistically large amount of knowledge about the structure of the economy on the part of the policymaker. Thus, from a practical policy perspective, it is more interesting to investigate the performance of a simpler rule that could then be studied in more detailed models. In addition, simple Taylor (1993) style rules have been advocated on the grounds that they perform well across a variety of models (Levin, Wieland and Williams (1999)).

We take as our starting point a Taylor-style rule (equation (3)), and augment it with a simple updating rule that captures the nonlinearities we found in Figure 2. For comparison, we also consider a linear updating rule, corresponding to the Gaussian prior and dashed lines in Figure 2. Although these simple updating rules will not be optimal in more complicated economic models, they may, like the Taylor rule, have the advantage of performing well across a variety of models.

We define the linear updating rule as follows (it is the optimal updating rule for the simple model of the previous section, assuming the Gaussian prior of Figure 1, except that the coefficients have been rounded):

$$
\hat{\mathrm{E}}_{\mathrm{t}} \mathrm{u}^{*}=\hat{\mathrm{E}}_{\mathrm{t}-1} \mathrm{u}^{*}+0.5\left(\mathrm{u}_{\mathrm{t}}-\hat{\mathrm{E}}_{\mathrm{t}-1} \mathrm{u}_{\mathrm{t}}\right)+0.35\left(\pi_{\mathrm{t}}-\hat{\mathrm{E}}_{\mathrm{t}-1} \pi_{\mathrm{t}}\right)
$$

The hat over the E emphasizes the fact that this simple updating rule will not be the true mathematical expectation in more general models.

We build our simple nonlinear updating rule as follows.

Intuitively, policymakers with the diffuse-middled prior are very willing to revise their beliefs about $\mathrm{u}^{*}$ near their original point estimate $\left(\mathrm{E}_{0} \mathrm{u}^{*}\right)$, but become increasingly more reluctant to do so, at the margin, the more they have revised their estimate of $u^{*}$ already. We match this qualitative feature by taking a weighted average of two linear rules: near $\mathrm{E}_{0} \mathrm{u}^{*}$, policymakers use a linear rule that is very willing to update estimates of $\mathrm{u}^{*}$, while further away from $\mathrm{E}_{0} \mathrm{u}^{*}$, policymakers use a linear rule that is much more reluctant to update $u^{*}$, at the margin, any further. The weight policymakers place on the reluctant, "stubborn" rule is greater the further is $\mathrm{E}_{\mathrm{t}-1} \mathrm{u}^{*}$ from $\mathrm{E}_{0} \mathrm{u}^{*}$. Thus: 


$$
\hat{E}_{t} u^{*}=\left(1-w_{t}\right) \cdot \text { open-minded rule } e_{t}+w_{t} \cdot \text { stubborn rule } t_{t}
$$

where $\mathrm{w}_{\mathrm{t}} \equiv \operatorname{Min}\left\{\left|\mathrm{E}_{\mathrm{t}-1} \mathrm{u}^{*}-\mathrm{E}_{0} \mathrm{u}^{*}\right|, 0.95\right\}$ and

open-minded rule:

$$
\hat{E}_{t} u^{*}=\hat{E}_{t-1} u^{*}+2.3 \cdot\left(0.5\left(u_{t}-\hat{E}_{t-1} u_{t}\right)+0.35\left(\pi_{t}-\hat{E}_{t-1} \pi_{t}\right)\right)
$$

stubborn rule:

$$
\hat{\mathrm{E}}_{\mathrm{t}} \mathrm{u}^{*}=\hat{\mathrm{E}}_{\mathrm{t}-1} \mathrm{u}^{*}
$$

The open-minded rule updates $130 \%$ more aggressively than the linear (i.e., Gaussian case) updating rule above. At the other end of the spectrum, the stubborn rule refuses to update any further (this is a limiting case which policymakers never actually reach). The "openmindedness" and "stubbornness" of these rules, and the weight function, were chosen so as to match the marginal updating prescriptions from Figure 2. In Figure 2A, we present this matchthe solid line depicts the simple nonlinear rule and the dashed line the optimal nonlinear rule from Figure 2. ${ }^{5}$ The approximation is of a similarly high quality for combinations of surprises in unemployment and inflation both (not shown).

Finally, before discussing our simulation results, the issue of Kalman filtering, learning, and attenuation in the updating rules needs to be mentioned. If policymakers' uncertainty about $u^{*}$ is regenerated every period (by shocks to $\mathrm{u}^{*}$, for example), then the coefficients in these updating rules would be close to optimal for every period going forward, and we could regard these updating rules as constant over time. However, we find it more realistic and interesting to assume that policymakers gradually learn about the true value of $u^{*}$ over time. Thus, policymakers will update by less and less each period as the cumulative number of observations increases. We calculate what this rate of attenuation is for optimal (i.e., Kalman) filtering for the Gaussian prior in the simple model, approximate it with a geometric decay (coefficient 0.94), and apply this rate of attenuation to both our simple linear and nonlinear updating rule coefficients over time.

\section{Simulations and Results}

Having defined our simple linear and nonlinear updating rules, we now test their performance in

5. To compare the simple rule (solid line) to the optimal rule (dashed line) in Figure 2A, we graph the simple rule as the sum of small marginal updates, using equation (5) at each step. In our quarterly simulations, the surprises in unemployment and inflation are almost always less than a few tenths, and thus the sum of small marginal updates captures very well policymakers' revision process. The optimal rule, as a function of the one-period surprise $\mathrm{u}_{\mathrm{t}}-\mathrm{E}_{\mathrm{t}-1} \mathrm{u}_{\mathrm{t}}\left(\mathrm{and} / \mathrm{or} \pi_{\mathrm{t}}-\mathrm{E}_{\mathrm{t}-1} \pi_{\mathrm{t}}\right)$, is most naturally thought of at a lower frequency, in which the policymaker is looking back over a longer period of time and updating by a greater amount (Swanson (2000b)). 
model simulations. We begin by simulating the rules' performance in the simple backwardlooking model of Section I. For comparison, we also test the performance of the rules in the forward-looking model of Rudebusch (2000). ${ }^{6}$ This model is essentially a weighted average of the backward-looking Rudebusch-Svensson (1999) model and the forward-looking "New Keynesian consensus" model favored by many recent authors (e.g., Clarida, Gali, Gertler (1999)). This feature of the model makes it easy for us to assess the rules' performance for different degrees of forward-lookingness in the economy. In ongoing work, we are evaluating the rules' performance in the larger, richer Monetary Studies Research model at the Board.

For each simulation, we fix a true value for $\mathrm{u}^{*}$ and calculate the losses that result from following the simple linear and nonlinear policies of Section II. For the forward-looking model, this requires a nonlinear rational expectations equation solver-we use the one from Fuhrer and Madigan (1997). Losses in each period are the equal-weighted sum of squared inflation deviations from target and squared unemployment deviations from $\mathrm{u}^{*}$. For each true value of $\mathrm{u}^{*}$, we run 10,000 simulations and calculate the average loss at each point in time.

Figure 3 presents the results for the simple backward-looking model of Section I, and Figure 4 presents analogous results for the fully forward-looking, "New Keynesian consensus" version of Rudebusch's model. In both figures, the single-period losses at a horizon of one year are plotted as a function of the true NAIRU $u^{*}$. The most important feature to note in Figures 3 and 4 is the intersection of the loss schedules for the linear and nonlinear policies. Neither rule completely dominates the other. For large deviations of the true NAIRU from policymakers' prior mean of 5 (the left and right extremes of the figures), the simple nonlinear rule updates very aggressively, and performs substantially better than the simple linear rule, because policymakers tend to arrive more quickly at a correct estimate for $\mathrm{u}^{*}$. For small deviations of the true NAIRU from policymakers' prior mean (the middle region of the figures), the simple nonlinear rule updates very aggressively, and incorrectly, in response to transitory shocks to $\mathrm{u}$ and $\pi$, and thus performs more poorly than the simple linear rule.

Which rule should be followed thus depends on policymakers' uncertainty about $\mathrm{u}^{*}$. If policymakers are not particularly uncertain about $\mathrm{u}^{*}$, then the simple nonlinear rule of the previous section seems to offer few benefits, and in fact even offers worse performance than the linear rule. However, if policymakers are very uncertain about the true value of $\mathrm{u}^{*}$ and consider a range of values fairly likely, the simple nonlinear rule offers greater robustness with respect to this uncertainty; in addition, it performs better on average (by about 5\%) over the range of values in Figure 4.

\section{Conclusions}

The Taylor rule was initially offered as a normative prescription. That is, it was designed to have

6. We use an Okun's Law of 2:1 to map output gaps to unemployment gaps in Rudebusch's model. 
excellent stabilization properties that were robust across different models and across a range of shocks to the economy. Subsequently, John Taylor concluded that the rule also had descriptive or predictive value; that is, it has described the way monetary policy has been conducted, at least over the previous decade.

The nonlinear policy rule we have developed in this paper may have the same two properties. First, we have shown that a simple nonlinear rule might outperform a linear rule during a period of heightened uncertainty about the NAIRU; this is its normative value. This result must nevertheless be viewed as only suggestive and preliminary, as it is based on only two very simple macroeconometric models. Further work will be necessary to determine how robust the results are across different models as well as in larger, more fully specified models.

Second, the nonlinear rule may describe the policies followed during this period better than the linear rule. There are several features of recent policy that seem to conform to the spirit of the nonlinear rule. First, the Board staff has continuously updated its estimate of the NAIRUspecifically the short-run NAIRU - during this period and the updated estimate of the NAIRU likely influenced to some degree the decisions of some members of the FOMC. Second, it appears that policymakers, for a while, were relatively tolerant of declines in the unemployment rate in a region around their initial prior-in effect, attenuating their response to changes in the unemployment rate. Third, when the unemployment rate fell to the lower end of a plausible range for the NAIRU, monetary policy moved preemptively and aggressively to slow growth and thereby reduce the risk of higher inflation. 


\section{References}

Braun, Steven. "Productivity and the NIIRU (and other Phillips Curve Issues)" Federal Reserve Board Wages, Prices and Productivity Working Paper No. 34, June 1984.

Clarida, Richard, Jordi Gali, and Mark Gertler. "The Science of Monetary Policy: A New Keynesian Perspective.” Journal of Economic Literature, December 1999, 37 (4), pp. 1661-1707.

Fuhrer, Jeffrey and Brian Madigan. "Monetary Policy When Interest Rates Are Bounded at Zero." Review of Economics and Statistics, November 1997, 79 (4), pp. 573-85.

Levin, Andrew, Volker Wieland and John Williams. "Robustness of Simple Monetary Policy Rules under Model Uncertainty," in John B. Taylor, ed., Monetary Policy Rules. Chicago: University of Chicago Press, 1999, pp. 263-99.

Lucas, Robert. "Expectations and the Neutrality of Money." Journal of Economic Theory, April 1972, 4 (2), pp. 103-24

Meyer, Laurence. "Q\&A on the Economic Outlook and Challenges Facing Monetary Policy," speech before the Philadelphia Council for Business Economics, September 8, 1999. http://www.federalreserve.gov.

Meyer, Laurence. "Structural Change and Monetary Policy," speech before the Joint Conference of the Federal Reserve Bank of San Francisco and the Stanford Institute for Economic Policy Research, March 3, 2000a. http://www.federalreserve.gov.

Meyer, Laurence. "The New Economy Meets Supply and Demand," speech before the Boston Economics Club, June 6, 2000b. http://www.federalreserve.gov

Orphanides, Athanasios and Volker Wieland. "Inflation Zone Targeting." European Economic Review, June 2000, 44 (7), pp. 1351-87.

Rudebusch, Glenn. "Assessing Nominal Income Rules for Monetary Policy with Model and Data Uncertainty.” Federal Reserve Bank of San Francisco Working Paper 2000-03, 2000.

Rudebusch, Glenn and Lars Svensson. "Policy Rules for Inflation Targeting." in John B. Taylor, ed., Monetary Policy Rules. Chicago: University of Chicago Press, 1999, pp. 203-46.

Svensson, Lars and Michael Woodford. "Indicator Variables for Optimal Policy." NBER Working Paper No. 7953, 2000.

Swanson, Eric. "On Signal Extraction and Non-Certainty-Equivalence in Optimal Monetary 
Policy Rules." Federal Reserve Board Finance and Economics Discussion Series 2000-32, 2000a.

Swanson, Eric. "Optimal Nonlinear Policy: Signal Extraction with a Non-Normal Prior." Working paper, Federal Reserve Board, 2000b.

Taylor, John. "Discretion versus Policy Rules in Practice," Carnegie-Rochester Conference Series on Public Policy, 39, pp. 195-214.

Wieland, Volker. "Monetary Policy and Uncertainty about the Natural Unemployment Rate," Federal Reserve Board Finance and Economics Discussion Series 1998-22, 1998. 
Figure 1: Some Possible Priors on the NAIRU

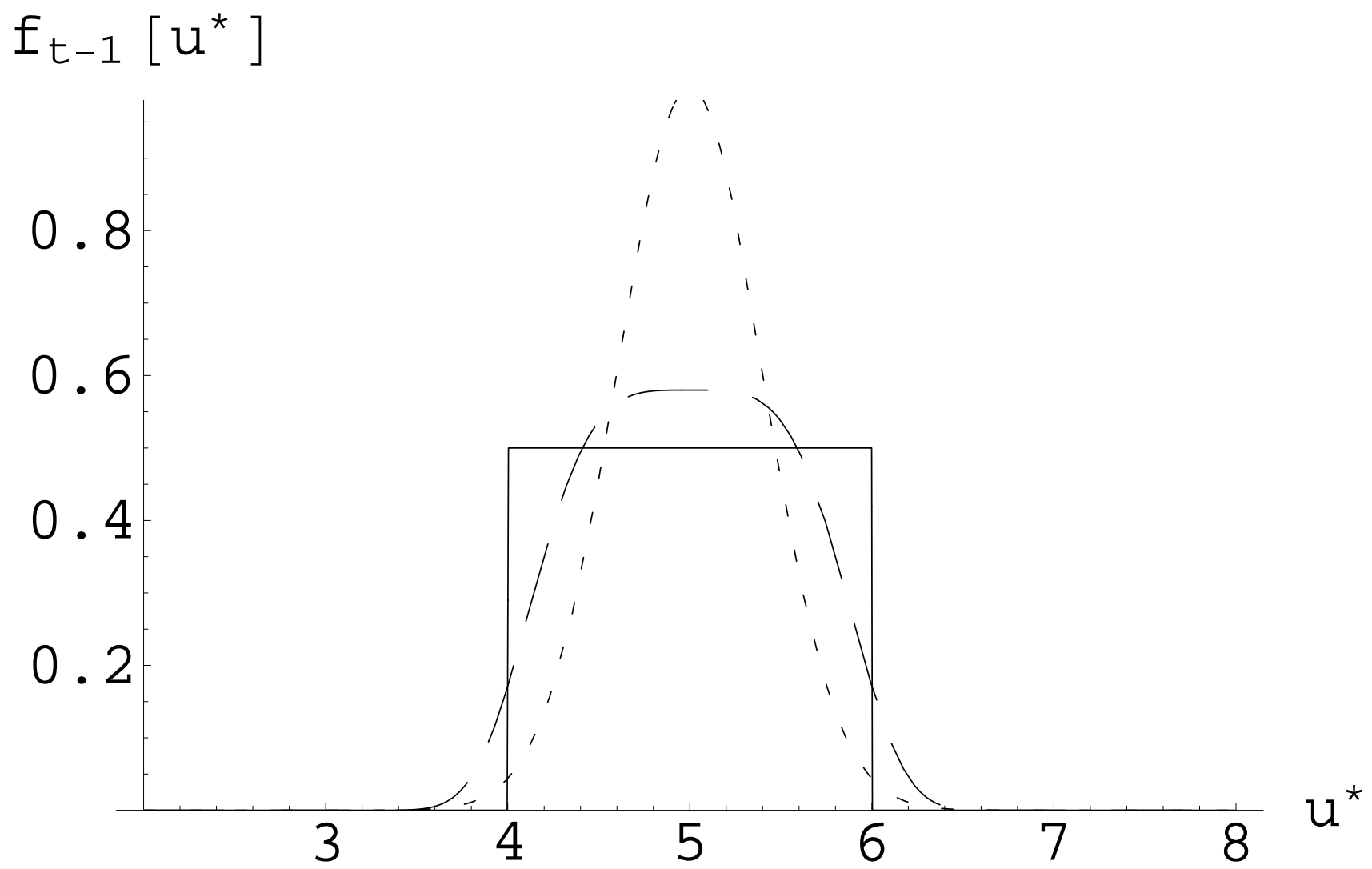


Figure 2: Optimal Updating, Uniform vs. Gaussian Priors
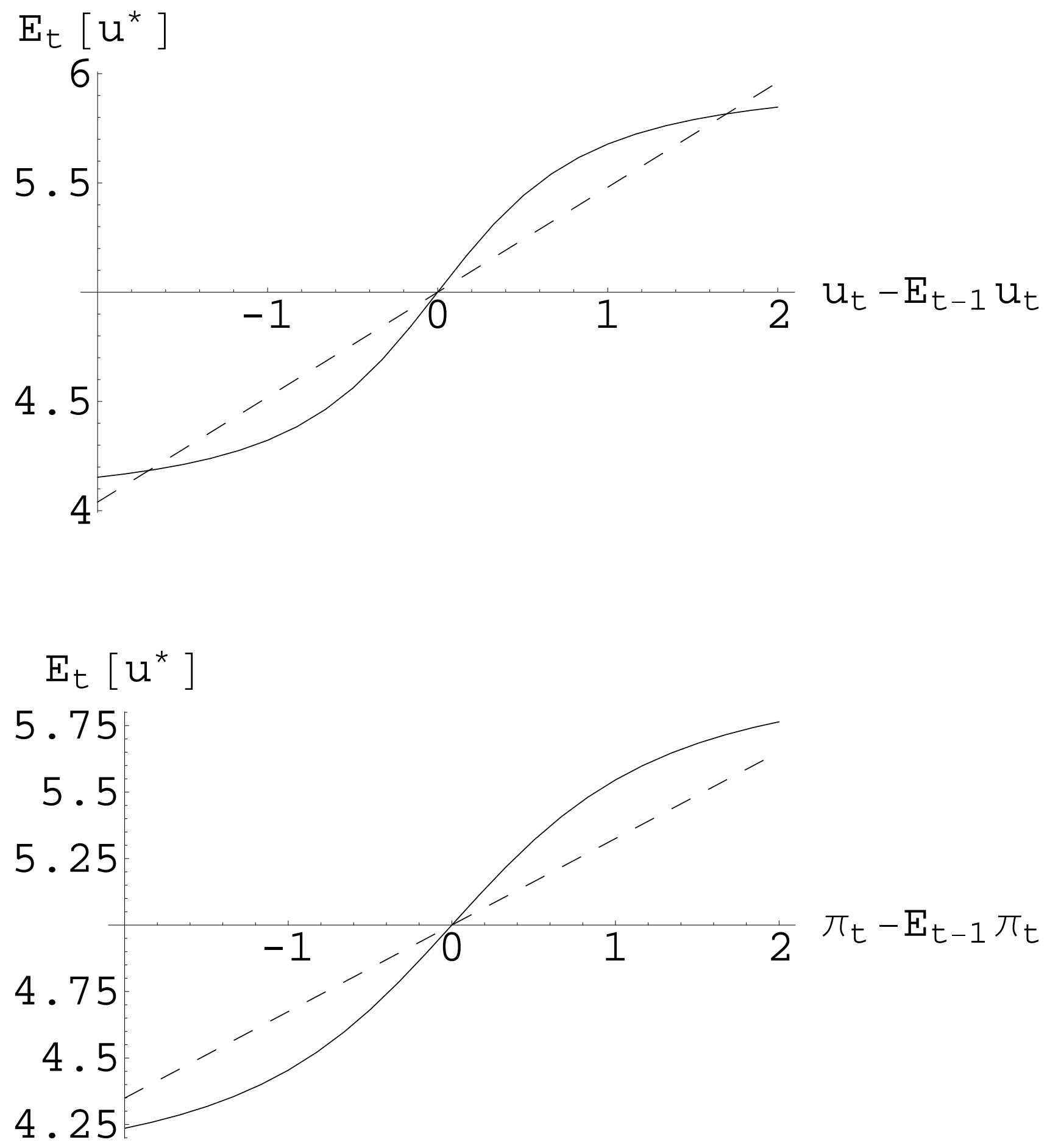


\section{Figure 2A: Simple Nonlinear Updating Rule vs. Optimal Updating}
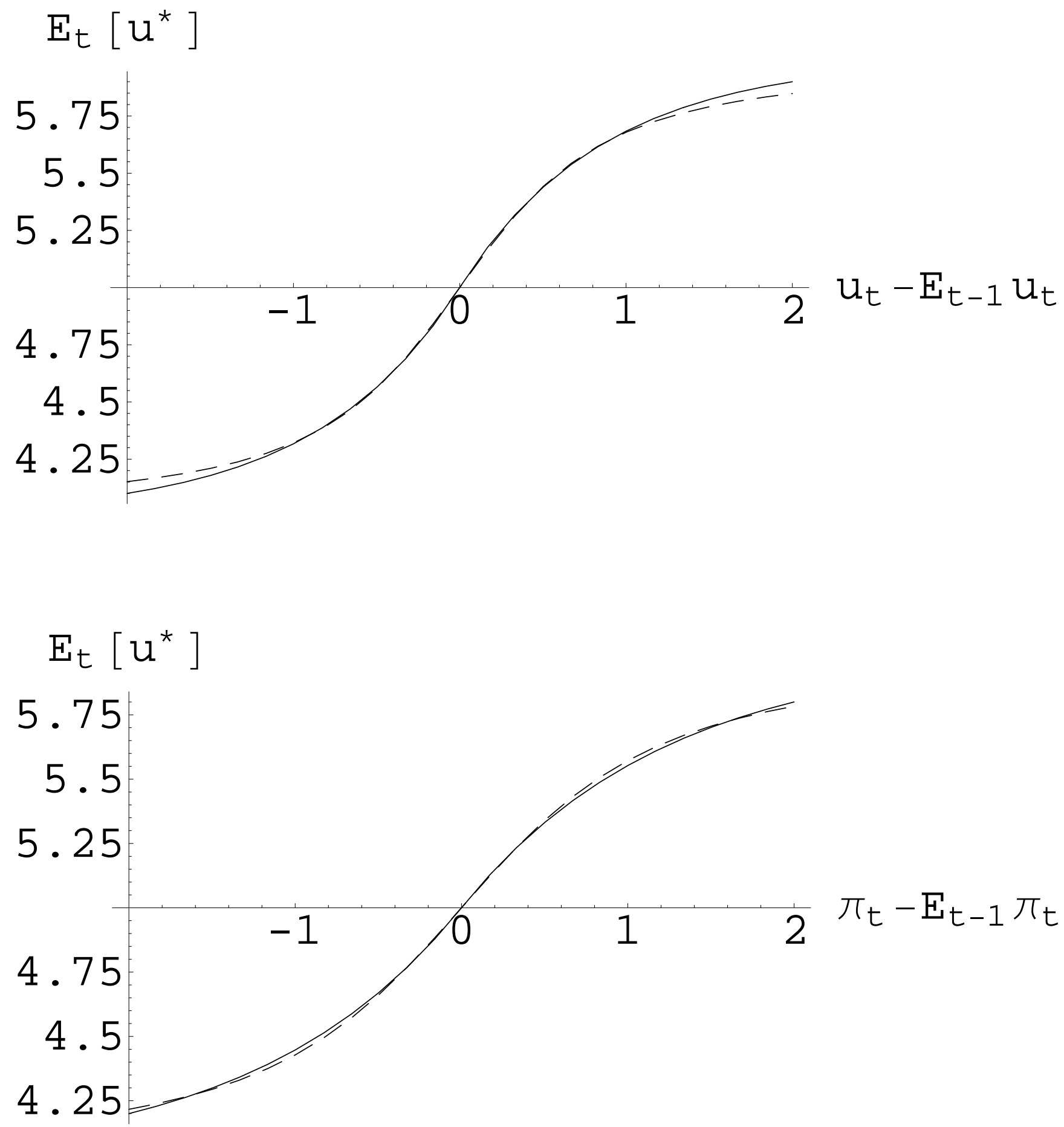
Figure 3: Losses from Nonlinear and Linear Policy Rules, Simple Backward-Looking Model

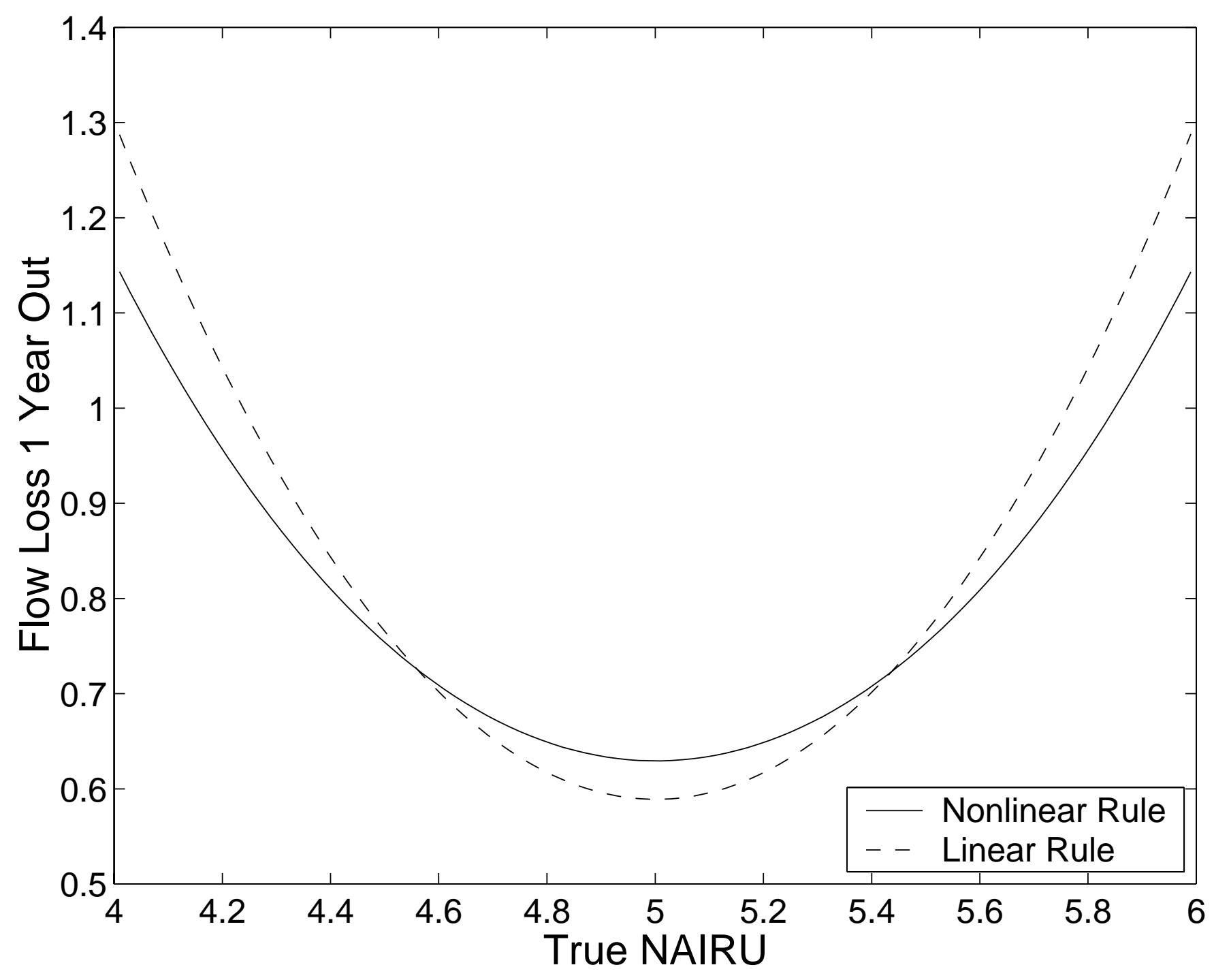




\section{Figure 4: Losses from Nonlinear and Linear Policy Rules, Fully Forward-Looking Model}

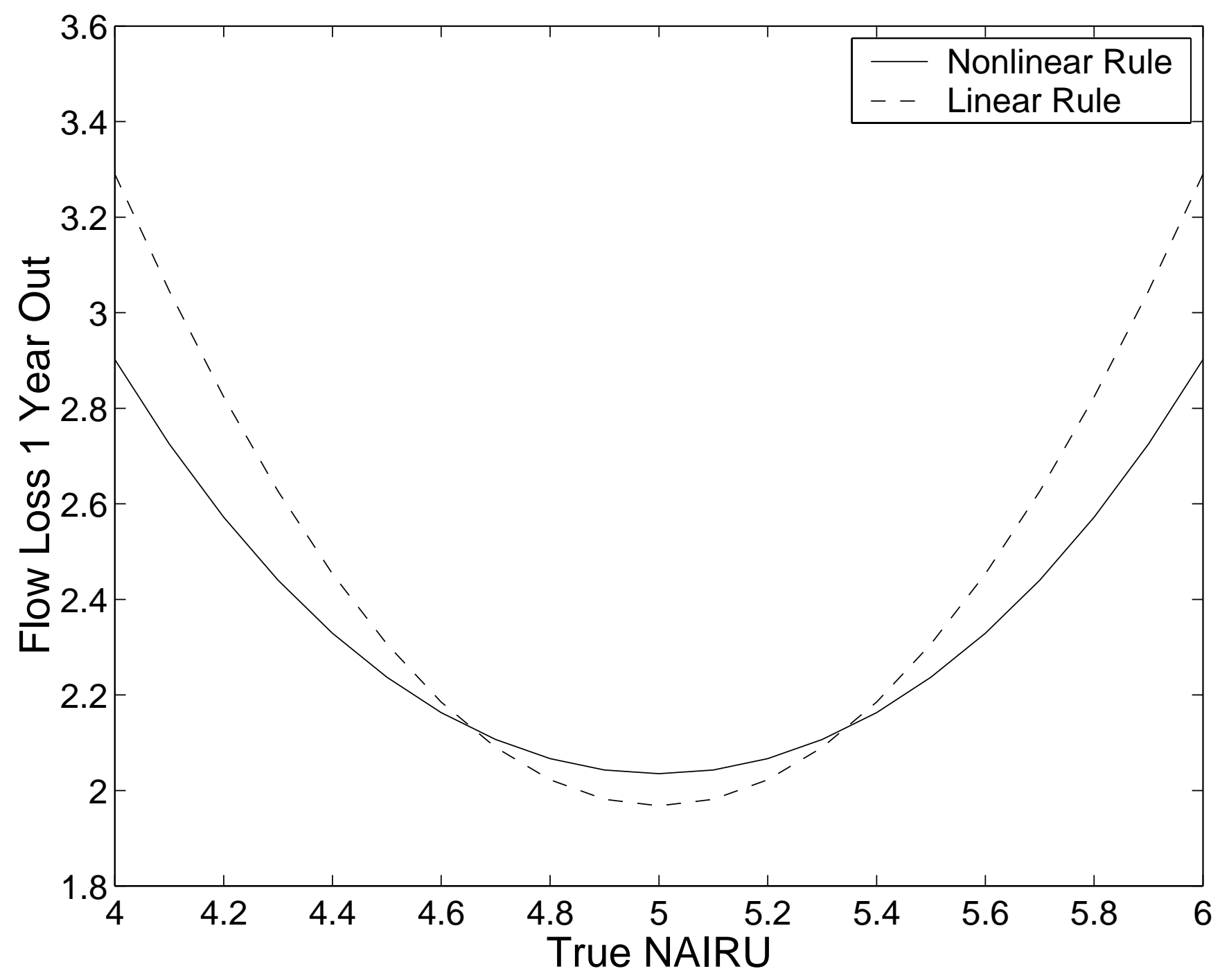

